\title{
Evaluating an Alternative Frame for Address-Based Sampling in Germany: The Address Database of the Deutsche Post Direkt
}

\author{
Sven Stadtmüller ${ }^{1}$ \\ Stefan Zins ${ }^{3}$ \\ Henning Silber ${ }^{1}$ \\ Christoph Beuthner ${ }^{1}$ \\ Tobias Gummer ${ }^{1,2}$ \\ Pablo Christmann ${ }^{1}$ \\ Matthias Sand ${ }^{1}$ \\ ${ }^{1}$ GESIS - Leibniz Institute for the Social Sciences \\ ${ }^{2}$ University of Mannheim \\ ${ }^{3}$ Institute for Employment Research
}

A revised version of this manuscript was published online first on March 31, 2022

in methods, data, analyses, available at: https://doi.org/10.12758/mda.2022.06 


\begin{abstract}
In Germany, the population register with individual addresses can be utilized for addressbased sampling. However, unlike in countries with a centralized register, local authorities in Germany administer their own registers. This not only makes sampling for a nation-wide survey more costly and cumbersome but may also result in gaps in the gross sample, as selected municipalities can refuse the use of their register for sampling purposes. If alternative municipalities to substitute refusals are not available, different sampling methods are required. With the present study, we aimed at testing the usability of the Address Database of the Deutsche Post Direkt (ADB-DPD) as an alternative frame for address-based sampling in Germany. We simultaneously carried out two surveys in the German city of Mannheim with gross samples of 3,000 each; one drawn from the city's population register and the other from the ADB-DPD. Our findings suggest that the ADB-DPD performs well, both in terms of survey response and up-to-dateness. Due to relatively low costs and the fast provision of addresses, the ADB-DPD can be particularly attractive for survey projects with limited budgets and tight schedules. However, these benefits come at considerable cost. First, the usage of the ADB-DPD is limited to self-administered surveys. More importantly, in the net sample of the DPD survey, women and young persons were considerably under-represented. This indicates coverage issues for which DPD provided no further information. Based on our analysis, we provide practical remarks on the usability of the ADB-DPD and suggest avenues for future research.
\end{abstract}

\title{
Keywords
}

address-based sampling, alternative sampling frame, population register, sample evaluation, sample composition 


\section{Introduction}

In many countries, researchers rely on official population registers for address-based sampling. Registers used for personal surveys should ideally include individual addresses. This not only avoids the selection of target persons within households or dwellings but also allows researchers to personalize their contacts from the beginning, which is known to be beneficial in terms of survey response (Dillman, Smyth, \& Christian, 2014).

Several countries, like the United States, Great Britain, or France, however, either completely lack official resident registers or their registers only include addresses of households (Poulain \& Herm, 2013; Link, Battaglia, Frankel, Osborn, \& Mokdad, 2008). In these instances, survey researchers have to settle for suboptimal registers or, when no register is available at all, utilize alternatives for address-based sampling. In the United Kingdom, for instance, the Postcode Address File (PAF) from the Royal Mail has been used as a sampling frame for several national and cross-cultural surveys, i.e., the European Social Survey (European Social Survey, 2017). In a similar vein, survey managers from the US often rely on address lists updated via the United States Postal Service (USPS) Computerized Delivery Sequence (CDS) for address-based sampling (Harter et al., 2016), even though this sampling frame is known to suffer from under-coverage (Amaya, Zimmer, Morton \& Harter, 2021).

Although register-based sampling is generally regarded as the gold standard for drawing representative samples of the residential population (Lohr, 2009), registers have their own challenges as well. In a survey among sampling experts in the participating countries of four European cross-cultural surveys, the experts mentioned under-coverage and inaccuracies as the main problems they encounter when using their population registers for sampling purposes (Maineri et al., 2017). Apart from that, access to population registers varies considerably across countries, with these sampling experts stating that commercial survey organizations in more than half of the surveyed countries have no access to the register. 
In Germany, researchers can rely on the population register with individual addresses for address-based sampling for academic surveys. At a first glance, this seems to be a comfortable situation. Yet, unlike in most countries with an official population register, the German register is decentralized with more than 5,000 local authorities administering population registers (Bundesministerium des Innern, für Bau und Heimat, n.d.). Therefore, sampling for a nation-wide personal survey in Germany is usually carried out at two stages. At the first stage, municipalities are selected based on a stratified random sample. At the second stage, all selected municipalities are contacted and asked to provide a random sample of their residents. In the German General Social Survey (ALLBUS) 2014, for instance, 148 municipalities were selected at the first stage (Wasmer, Blohm, Walter, Jutz, \& Scholz, 2017). For building the gross sample at the second stage, it is easy to imagine that, corresponding with such a large number of local authorities is a time-consuming process. Additionally, most municipalities charge a fee for drawing and transmitting a random sample from their register. In sum, the decentralization of the German register makes sampling more demanding and a rather costly process in terms of time and funds. Utilizing the German population register to draw a sample may thus not be feasible for research projects with small budgets or tight schedules.

Most importantly, access to the population register depends on autonomous decisions made by each municipality. According to Section 46, Paragraph 1 of the German Federal Act on Registration, access to registration information from the residential registration offices is only allowed if the applicant acts in the public interest. This ambiguity leaves a certain leeway for municipalities, resulting in some of them refusing to provide the desired addresses if the research purpose is not deemed to be in the public's interest for various reasons. Although this share appeared to be rather low in the past ${ }^{1}$, we suspect the raised awareness for public

\footnotetext{
${ }^{1}$ In the German General Social Survey in 2014, for instance, 6 out of 148 municipalities did not provide addresses (Wasmer et al. 2017).
} 
privacy, because of the General Data Protection Regulation of the European Union, to increase noncompliance of municipalities. If a municipality refuses to provide addresses, a substitute is used. However, substitution is methodologically problematic, especially if no structurally equivalent municipality surrogate exists (e.g., for the capital of a federal state). Non-response on the municipality level may result in selection error that can have a stronger effect than non-response on an individual level. To avoid this, alternative methods are required. These often include other sampling frames (for that particular municipality) or other sampling procedures such as random route. However, these alternatives often suffer from coverage errors and/or unknown inclusion probabilities that may lead to biased estimates.

With the present study, we tested an alternative sampling frame available in Germany: the Address Database of the Deutsche Post Direkt (ADB-DPD). The DPD is a subsidiary of the Deutsche Post, the central deliverer of mail and parcels in Germany. The company is specialized on address marketing and administers the largest commercial address database in Germany, including 220 million older and current entries of individual addresses all over the country, with its population of roughly 83 million people (Deutsche Post Direkt, 2020). However, since DPD does not provide information on coverage of its frame and on how addresses are obtained, knowledge on its usability for survey sampling is lacking. To this end, we carried out a study to explore the following two research questions:

- Is the ADB-DPD a viable alternative for address-based sampling, in particular for projects that cannot afford drawing a random sample from the population register?

- Is the ADB-DPD a viable complement for address-based sampling for those municipalities that refuse to provide addresses from their population register? In the next section, we describe the methods of our study and introduce the criteria used for evaluation. Thereafter, we present our results, before reflecting on the usability of the ADB-DPD for address-based sampling in Germany. 


\section{Data and Methods}

\section{Surveys}

From November 2019 to February 2020, we simultaneously conducted two surveys in the city of Mannheim, located in the federal state of Baden-Wuerttemberg in southwestern Germany. Mannheim belongs to the prospering Rhine-Neckar Metropolitan Region with a high share of specialized jobs, especially in technology and pharmacy. The city is characterized by a high share of students (approximately 10 percent of the residential population, compared to 3 percent in the general population) and diversity, with roughly 45 percent of the residents having a migration background (Stadt Mannheim, n.d.).

For the first survey (hereafter referred to as the "register survey"), we drew 3,000 individual addresses from the city's population register, whereas for the second one (the "DPD survey") the same amount of addresses was drawn from the ADB-DPD. For both surveys, simple random samples of all persons aged 18 years and above were drawn from each sampling frame. Before we initially contacted our target persons, our field service provider carried out a duplicate check of the addresses and omitted 20 cases that were included in the address files from both origins.

Apart from differences in the cover letter (explained in more detail in the following section), both surveys were identical in terms of recruitment, field time, and questionnaire. We carried out a self-administered mixed-mode survey (web and mail) and randomly allocated target persons from each sampling frame to one of eight experimental groups, representing combinations of mode choice sequence (sequential vs. concurrent) and small prepaid monetary incentives offered in the first or second contact. In both surveys, all groups had the same sample size. As these experiments were independent from the sampling frame and go beyond the scope of the present study, we do not report these findings here.

The survey was introduced to the target persons as a community survey dealing with life quality in Mannheim but also included other topics such as political attitudes, personality 
traits, and the perception of surveys. The questionnaire took roughly 30 minutes to complete. The paper questionnaire could be returned in an enclosed prepaid return envelope. The webbased questionnaire was optimized for mobile devices.

\section{Operationalization}

To assess the performance of the ADB-DPD, we drew on the following criteria.

Feasibility: This criterion includes measures that are relevant for survey planning and budgeting, as well as requirements and limitations for the implementation of surveys and for fieldwork, as a consequence of relying on the ADB-DPD for sampling purposes. More specifically, these measures are: (1) the duration of address provision, (2) the costs for drawing a sample, (3) the usability of survey modes, and (4) restrictions for fieldwork.

Up-to-dateness: Here, we summed up the proportion of target persons for whom: (1) the invitation letter could not be delivered by the postal service, due to an incorrect address, death or relocation, (2) the invitation letter could be delivered, but we gained knowledge (e.g., from relatives) that the target person has deceased or moved away (and the postal service was not aware of this).

Survey Response: Participation in both surveys was measured with AAPOR Response Rate 2 based on the guidelines proposed by AAPOR (2016).

Sample Composition: Comparing the composition of the net samples of both surveys may indicate whether the ADB-DPD suffers from coverage problems and systematically excludes groups of the target population. To this end, we first analyzed the composition of the net samples with regard to gender and age. For these two variables, we also had information on their distribution in the target population (Stadt Mannheim, 2020). For the means of comparison with the official data, we recoded age into five groups (18-24, 25-29, 30-64, 6579, 80 and older). Gender was coded dichotomously ( $1=$ females, $0=$ males $)$. 
Second, we compared the two samples with regard to migration background, formal education, marital and employment status, place of birth, and second residence. For measuring migration background, each respondent was asked whether herself, her mother or her father had immigrated to the current territory of the Federal Republic of Germany after 1955. We created a dummy variable indicating if this was the case for either one of the three persons. Formal education was also coded as a dummy variable, with the value 1 indicating that the respondent had a higher-education qualification (Abitur or Fachabitur). We created similar dummies indicating whether the respondent stated to be married, to be employed, to live in Mannheim since birth, and to have a second residence in Germany. For these variables, we compared the two net samples, as no official statistics are available for Mannheim (with the register survey as reference).

In addition, we compared the net samples with respect to a set of substantive variables. These variables cover a wide range of topics commonly asked in general social science surveys.

- Self-reported political interest measured on a seven-point scale, ranging from "not at all" to "very much".

- External political efficacy measured based on the agreement to the statement "Politicians do care about what people like me think" on a seven-point scale, ranging from "fully disagree" to "fully agree".

- Abstention from voting measured based on the question which political party a respondent would vote for if a national election took place the next Sunday $(1=$ would abstain, $0=$ would vote, missing value $=$ not allowed to vote $)$.

- Voting intention for the Conservatives measured based on the voting question with a dummy variable indicating whether respondents stated that they would vote for the CDU party $(1=$ vote for CDU, $0=$ vote for other party, missing value $=$ would abstain or not allowed to vote). 
- Interpersonal Trust measured based on the response to the statement "Generally speaking, do you think that most people can be trusted or that you cannot be too careful in dealing with other people?" $(1=$ most people can be trusted, $0=$ cannot be too careful).

- Institutional Trust measured based on three items; trust in the federal government, trust in the media and trust in political parties, with each item measured on a sevenpoint scale, ranging from "do not trust at all" to "fully trust".

- Big Five personality traits measured based on the BFI-10 short scale (Rammstedt \& John, 2007). Respondents answered the 10 items on a seven-point scale ranging from “does not apply at all" to "fully applies". For each dimension (openness, conscientiousness, extraversion, agreeableness, neuroticism), we computed the mean of the two items measuring it.

\section{Results}

\section{Feasibility}

Duration of address provision: The DPD was able to provide the requested addresses within five business days. Due to the centralized setup of the ADB-DPD, addresses from a larger set of municipalities (across Germany) would have probably been provided in a similar timely fashion. For drawing a nation-wide sample from the population register, German survey managers usually estimate up to three months to receive addresses from all selected municipalities.

Costs for drawing a sample: For up to 10,000 individual addresses, the cost per 1,000 addresses were 84 Euro (as of October 2019), irrespective of whether these addresses shared the same place of residence or were spread all over Germany. However, the minimum contract value was fixed at 1,000 Euro per delivery. Since our survey used the same addresses twice (i.e., for the initial contact and for a reminder), the DPD regarded this as two deliveries 
and charged an additional fee (of 250 Euro, as of October 2019) for data storage and for a check regarding the up-to-dateness of the addresses prior to the second delivery. Thus, for a nation-wide survey that fully relied on the ADB-DPD for address-based sampling with a gross sample of 10,000 target persons and three scheduled contact attempts, the cost of sampling would have amounted to 3,500 Euro ( $3 \mathrm{x}$ the minimum contract value, plus the additional fee for the second and third delivery/contact). Based on our own experiences and on an estimate from an experienced survey manager from a German fieldwork agency, drawing a sample of similar size from the population register amounts to approximately 30,000 Euro only for acquiring the addresses. Consequently, when drawing a sample of residents from all over Germany, relying on the ADB-DPD is significantly cheaper and the data is provided much faster compared to the population register. However, researchers considering using the ADBDPD as a substitute for singular, noncompliant municipalities, drawing a random sample of their residents would also amount to 3,500 Euro (for three contacts), even if only 500 addresses from only five municipalities were needed. This is, again, due to the fixed minimum contract value per delivery. Thus, for small substitute samples of a limited number of municipalities, the relative costs per case are considerably higher.

Usability of survey modes: In terms of feasibility, the ADB-DPD came with a major downside: We did not receive the addresses directly but had to engage a print service provider that, in turn, concluded a contract with the DPD for receiving and processing the addresses. Although this did not affect our fieldwork management negatively ${ }^{2}$, it considerably limits the databases' usability since sampling via the ADB-DPD is not feasible for face-to-face surveys. Rather, the use of the ADB-DPD is limited to self-administered surveys with mailed invitations. Moreover, it was not possible to further reduce survey costs by engaging our own

\footnotetext{
${ }^{2}$ To administer responses, each address was assigned to an eight-digit string code by our print service provider. These codes were printed on the paper questionnaire and were also used as passwords to access the online questionnaire.
} 
staff (e.g., student assistants) for preparing the letters as all operative work with survey materials had to be done by the contracted print service provider.

Limitations in recruitment: Researchers are bound to terms and conditions of the DPD when purchasing addresses. This has two important implications. The first implication being the content of the cover letter. The DPD demanded a rather lengthy text passage on data protection issues that had to be placed readily visible on the first page of our cover letter (770 characters including blanks). This text was pre-written, could not be changed in its content, and was framed for the common use of the ADB-DPD: advertising. The additional textual information also could not be integrated in accompanying material like in the data privacy sheet. This not only reduced the space in the cover letter for providing relevant information about the survey but also made us afraid that target persons doubted the integrity of the survey, especially because the (standardized) text suggested the content of the letter to serve advertising purposes. Finally, we had to submit all materials to the DPD (e.g., the cover letter, the data privacy sheet, the questionnaire etc.) in advance to obtain approval for mailing them to our target persons. However, this did not prolong the preparation time before fieldwork since we submitted our materials and received the approval on the same business day.

The second limitation is that we were restricted on when to re-contact our target persons (for sending reminders). More precisely, it was only possible to contact the same addresses again four weeks after the initial contact. In the meantime, the DPD checked whether some recipients had requested for a deletion (with the respective procedure clarified in the aforementioned textual information). For survey managers, this means that a subsequent contact attempt can only be carried out four to five weeks after the previous one ${ }^{3}$. This increases field duration and likely diminishes the effect of incentives and other motivational material provided with the first contact attempt.

\footnotetext{
${ }^{3}$ In our study, we only used one reminder and therefore did not investigate whether a third delivery of the same addresses would have been possible. Thus, we suggest that researchers, who plan to purchase addresses from the DPD and to contact their target persons more than twice, to resolve this issue with the company in advance.
} 


\section{Up-to-dateness}

The proportion of (potentially) outdated addresses was 10.1 percent for the register survey and slightly lower for the DPD survey (9.3 percent). According to a two sample test for equal proportions, this difference did not fall below conventional thresholds for statistical significance $(\mathrm{z}=1.01, \mathrm{p}>0.05)$.

\section{Survey Response}

Across both samples, 24.3 percent of the target persons participated in our surveys (AAPOR RR2). The response rate in the DPD survey (26.1 percent) was significantly higher than in the register survey $(22.3$ percent, $\mathrm{z}=3.26, \mathrm{p}<0.01)$. Thus, the additional text on the cover letter, implicitly declaring the survey as marketing communication, seems not to have affected survey response negatively.

\section{Sample Composition}

According to Table 1, the share of females in the target population (official data) was 49.7 percent. In the register survey, this share was slightly lower (47.9 percent), but still considerably higher than in the DPD survey with only 39.0 percent of all respondents being female. Based on a one sample test on the equality of proportions, women were significantly underrepresented in the DPD survey as compared to the official data $(\mathrm{z}=-5.65, \mathrm{p}<0.001)$.

Table 1: Gender and age distribution in the target population (official data) and in the two surveys

\begin{tabular}{lcccccc} 
Demographic variables & $\begin{array}{c}\text { Official } \\
\text { Data }\end{array}$ & $\begin{array}{c}\text { Register } \\
\text { Survey }\end{array}$ & $\begin{array}{c}\text { DPD } \\
\text { Survey }\end{array}$ & $\begin{array}{c}\text { p (Register } \\
\text { vs. DPD) }\end{array}$ \\
\hline Females & 49.7 & 47.9 & $\mathrm{~ns}$ & 39.0 & $* * *$ & $* *$ \\
\hline Age & & & & & & \\
$18-24$ & 11.6 & 13.6 & $\mathrm{~ns}$ & 1.3 & $* * *$ & $* * *$ \\
$25-29$ & 9.8 & 10.9 & $\mathrm{~ns}$ & 2.0 & $* * *$ & $* * *$ \\
$30-64$ & 56.9 & 54.5 & $\mathrm{~ns}$ & 62.4 & $* *$ & $* *$ \\
$65-79$ & 14.8 & 15.9 & $\mathrm{~ns}$ & 27.7 & $* * *$ & $* * *$ \\
80 and above & 6.9 & 5.2 & $\mathrm{~ns}$ & 6.6 & $\mathrm{~ns}$ & $\mathrm{~ns}$ \\
\hline
\end{tabular}

Note. Differences in demographic variables between the Register survey/DPD survey and official data were tested based on (two-sided) one sample tests on the equality of proportions. Differences in demographic variables between the two surveys were tested based on a (two-sided) two-sample test for equal proportions. $\mathrm{ns}=$ not significant; $* \mathrm{p}<0.05 ; * * \mathrm{p}<0.01 ; * * * \mathrm{p}<0.001$. 
With regard to age, the distribution of respondents in the register survey was not significantly different from the one in the target population. In the DPD survey, however, the age distribution was heavily skewed towards older people with a share of people aged 65 to 79 that was almost twice as high as in the target population. On the contrary, the share of respondents aged below 30 was only 3.3 percent in the net sample of the DPD survey, whereas in the target population 21.4 percent belonged to this age group. This indicates that in the ADB-DPD older people are considerably over-represented.

Regarding further socio-demographics (see Table 2), the share of respondents with a migration background was rather low in both surveys. This finding is a common phenomenon, especially in self-administered surveys (Salentin, 2014). In the DPD survey, this share was 11.7 percent but even significantly lower than in the register survey ( 21.7 percent, $z=4.58$, $\mathrm{p}<0.001)$.

We acknowledge that researchers frequently use weighting to control for differences in the sample composition if reference distributions are available. Accordingly, we ran additional models in which we controlled for the different composition regarding age and gender in both samples. In this multivariate model, the difference in the share of respondents with a migration background between both surveys reduced but remained remarkably high. When it comes to formal education, without controls for gender and age, the register survey had a significantly higher share of respondents with higher education (61.5 percent in the register survey as opposed to 51.7 percent in the DPD survey, $\mathrm{z}=3.44, \mathrm{p}<0.001)$. The multivariate model, however, indicates that these differences were only attributable to differences in the sample composition with regard to age. Yet, even after controlling for gender and age, respondents in the DPD survey had a significantly higher probability of being married, of being employed and of living in Mannheim since birth. For these variables, the net sample of the DPD survey significantly differed from the one of the register survey that we considered the reference distribution in these analyses. 
Table 2: The distribution of other demographics in both surveys without and after controlling for age and gender

\begin{tabular}{lccccccc} 
& \multicolumn{3}{c}{$\begin{array}{c}\text { Estimates without } \\
\text { controlling for age and } \\
\text { gender }\end{array}$} & \multicolumn{2}{c}{$\begin{array}{c}\text { Estimates after controlling } \\
\text { for age and gender }\end{array}$} \\
\hline Demographic variables & $\begin{array}{c}\text { Register } \\
\text { Survey }\end{array}$ & $\begin{array}{c}\text { DPD } \\
\text { Survey }\end{array}$ & p & $\begin{array}{c}\text { Register } \\
\text { Survey }\end{array}$ & $\begin{array}{c}\text { DPD } \\
\text { Survey }\end{array}$ & p \\
\hline Migration background & 21.7 & 11.7 & $* * *$ & 19.4 & 13.1 & $* *$ \\
High formal education & 61.5 & 51.7 & $* * *$ & 54.4 & 57.5 & $\mathrm{~ns}$ & $* * *$ \\
Living in Mannheim since birth & 32.4 & 51.0 & $* * *$ & 32.6 & 50.8 & $* * *$ \\
Married & 46.5 & 66.2 & $* * *$ & 51.8 & 61.8 & ns \\
Second residence in Germany & 6.6 & 8.1 & $\mathrm{~ns}$ & 5.9 & 9.0 & $\mathrm{~ns}$ \\
Employed & 58.9 & 57.1 & $\mathrm{~ns}$ & 50.2 & 63.0 & $\mathrm{~ns}$ \\
\hline
\end{tabular}

Note. All estimates are predicted proportions based on logistic regression models with the demographic variable as dependent variable and sample as independent variable.

ns=not significant; $* \mathrm{p}<0.05 ; * * \mathrm{p}<0.01 ; * * * \mathrm{p}<0.001$.

Finally, Table 3 shows differences between the register and the DPD survey with respect to substantive variables. Similar to above, we report differences with and without controls for differences in the net samples with regard to age and gender. Without controls for age and gender, we found responses in the DPD survey to show higher levels of political interest and lower levels of external efficacy. When controlling for age and gender, differences in self-reported political interest disappeared. Yet, in this scenario, the gap in external political efficacy remained and differences in institutional trust were even more pronounced. While we found significant differences with and without controls for age and gender, we would like to note that we consider the magnitude of these differences to be small. 
Table 3: Means/Proportions of substantive items in both surveys without and after controlling for age and gender

\begin{tabular}{|c|c|c|c|c|c|c|}
\hline \multirow[b]{2}{*}{ Substantive Items } & \multicolumn{3}{|c|}{$\begin{array}{l}\text { Estimates without } \\
\text { controlling for age and } \\
\text { gender }\end{array}$} & \multicolumn{3}{|c|}{$\begin{array}{l}\text { Estimates after controlling } \\
\text { for age and gender }\end{array}$} \\
\hline & $\begin{array}{l}\text { Register } \\
\text { Survey }\end{array}$ & $\begin{array}{c}\text { DPD } \\
\text { Survey }\end{array}$ & $\mathbf{p}$ & $\begin{array}{l}\text { Register } \\
\text { Survey }\end{array}$ & $\begin{array}{c}\text { DPD } \\
\text { Survey }\end{array}$ & $\mathbf{p}$ \\
\hline $\begin{array}{l}\text { Self-reported political interest } \\
1=\text { not at all; } 7=\text { very much }\end{array}$ & 4.98 & 5.22 & $* *$ & 5.08 & 5.13 & ns \\
\hline $\begin{array}{l}\text { Politicians do care about what people } \\
\text { like me think (external efficacy) } \\
1=\text { fully disagree; } 7 \text { = fully agree }\end{array}$ & 3.01 & 2.69 & $* * *$ & 2.98 & 2.72 & $* *$ \\
\hline Abstention from voting & $7.6 \%$ & $5.6 \%$ & ns & $8.0 \%$ & $5.3 \%$ & ns \\
\hline Voting intention for the Conservatives & $19.3 \%$ & $24.5 \%$ & $*$ & $22.2 \%$ & $22.2 \%$ & ns \\
\hline $\begin{array}{l}\text { Interpersonal Trust } \\
0=\text { one cannot be too careful; } 1=\text { most people can } \\
\text { be trusted }\end{array}$ & $56.2 \%$ & $56.4 \%$ & ns & $54.3 \%$ & $58.0 \%$ & $\mathrm{~ns}$ \\
\hline \multicolumn{7}{|l|}{ Institutional Trust } \\
\hline $\begin{array}{l}\text { Trust in the federal government } \\
1=\text { do not trust at all; } 7=\text { fully trust }\end{array}$ & 4.07 & 3.96 & ns & 4.12 & 3.92 & $*$ \\
\hline $\begin{array}{l}\text { Trust in the media } \\
1=\text { do not trust at all; } 7=\text { fully trust }\end{array}$ & 3.59 & 3.65 & ns & 3.66 & 3.58 & $\mathrm{~ns}$ \\
\hline $\begin{array}{l}\text { Trust in political parties } \\
1=\text { do not trust at all; } 7=\text { fully trust }\end{array}$ & 3.27 & 3.14 & ns & 3.29 & 3.12 & $*$ \\
\hline \multicolumn{7}{|l|}{ Personality Traits (Big Five) } \\
\hline $\begin{array}{l}\text { Openness to experience } \\
1=\text { very low; } 7=\text { very high }\end{array}$ & 4.75 & 4.59 & ns & 4.72 & 4.62 & ns \\
\hline $\begin{array}{l}\text { Conscientiousness } \\
1=\text { very low; } 7=\text { very high }\end{array}$ & 5.38 & 5.48 & ns & 5.44 & 5.43 & ns \\
\hline $\begin{array}{l}\text { Extraversion } \\
\text { 1= very low; } 7=\text { very high }\end{array}$ & 4.49 & 4.37 & ns & 4.43 & 4.42 & ns \\
\hline $\begin{array}{l}\text { Agreeableness } \\
1=\text { very low; } 7=\text { very high }\end{array}$ & 4.31 & 4.35 & ns & 4.32 & 4.34 & $\mathrm{~ns}$ \\
\hline $\begin{array}{l}\text { Neuroticism } \\
1=\text { very low; } 7=\text { very high }\end{array}$ & 3.39 & 3.35 & $\mathrm{~ns}$ & 3.33 & 3.41 & ns \\
\hline
\end{tabular}

Note. All estimates are predicted means/proportions based on linear/logistic regression models (logistic regression models were estimated for "Abstention from voting", "Voting intention for the Conservatives", and "Interpersonal Trust") with the substantive item as dependent variable and sample as independent variable.

$\mathrm{ns}=$ not significant $* \mathrm{p}<0.05 ; * * \mathrm{p}<0.01 ; * * * \mathrm{p}<0.001$.

\section{Discussion}

With the present study, we aimed at testing the usability of the ADB-DPD as a sampling frame for scientific surveys. In many countries, commercial enterprises, especially postal service providers, have specialized on collecting and selling addresses of their residential population. In Germany, the DPD administers the largest database that is mainly used for marketing purposes. However, this database can also serve as a frame for address-based 
sampling for nation-wide surveys since addresses can be randomly drawn from all current entries all over the country.

The starting point for our study was the assumption that sampling from the official population register is the gold standard for drawing representative surveys of the German residential population. Nevertheless, we imagined the ADB-DPD to be attractive as a complement or even as an alternative sampling frame in two scenarios. In the first scenario, survey projects have limited resources in terms of time and funds but need to include target persons with a high regional diversification or even aim to carry out a nation-wide survey. In the second scenario, survey projects are well equipped with resources to comply with the gold standard for sampling but are facing some municipalities refusing to provide the desired addresses. In this scenario (and particularly in cases where these communities cannot be easily substituted), the ADB-DPD may complement the population register for address-based sampling. For these potential scopes of application, our study aimed at providing a first assessment of the usability of the ADB-DPD as a frame for address-based sampling, especially because DPD provides no information on the coverage of their database.

A key limitation of the ADB-DPD is that it is meaningfully usable as a sampling frame only for self-administered surveys. This is because researchers do not receive the addresses directly but can only communicate with their target persons via a print service provider. Of course, this considerably limits the scope of application. However, given this important restriction, our results were rather promising in terms of feasibility. Due to the centralized setup of their database, addresses from all over Germany can be randomly drawn and provided by the DPD within five business days and at low costs. The ADB-DPD appears especially cost-effective for nation-wide survey projects that consider to fully rely on this sampling frame. In contrast, when a random sample is needed for only a small number of noncompliant municipalities that cannot be substituted (which we consider the most important case for scientific surveying), sampling via the ADB-DPD is rather expensive mainly due to 
the fixed minimum contract value. Moreover, due to DPD insistence on business secrets, the generation of the sampling frame is essentially a black box which results in survey error to not be computable (e.g., coverage error).

Having said that, the ADB-DPD performed well in terms of survey response and upto-dateness. With regard to survey response, the DPD survey even yielded a significantly higher response rate. This outcome is surprising, given that DPD required adding more data privacy information to the cover letter. Moreover, the rate of undeliverable invitation letters was slightly lower in the DPD survey.

Regarding the sample composition, we found a substantial under-representation of women and young people in the DPD survey. Given that we drew a simple random sample from both frames and administered the similar survey, this may indicate that the ADB-DPD suffers from coverage error for these demographic groups. Turning to substantive variables, we found some differences between the net samples of our two surveys - before and after controlling for age and gender. However, these appeared to be of low magnitude.

Overall, we would like to caution that using the ADB-DPD comes with its own challenges and uncertainties, especially regarding how addresses are obtained and how well the database covers the residential population. Regarding the feasibility of ADB-DPD for sampling purposes, it seems like an option for smaller research projects that cannot afford to draw a nation-wide sample from the population register and operate on a tight schedule. This holds especially true if, the estimation of valid parameters for the residential population is not of high priority but rather experimentation.

Our study can be extended in different ways. First, we encourage future research to compare different approaches to the gold standard and detail each alternative's pros and cons. If a noncompliant municipality cannot be substituted, there will be a trade-off between having no addresses for this regional unit (i.e. risking systematic under coverage) and drawing on alternative frames with their own challenges and possible errors. Like in our study, we 
suggest investigating this question by fielding similar surveys in parallel in the same regional units using different methods of sampling.

Second, our study focused on the municipality of Mannheim. While our findings might hold true for other cities or regions of Germany, replication studies are required. Such studies should also aim to cover different topics. Our survey was framed as a community survey that covered a diverse set of social science question content. Yet, it would be interesting to see how well the ADB-DPD would perform for specific topics (e.g., election studies) or questionnaires without a topic of local relevance. 


\section{References}

Amaya, A., Zimmer, S., Morton, K., \& Harter, R. (2021). Does Undercoverage on the U.S. Address-based Sampling Frame Translate to Coverage Bias? Sociological Methods \& Research, 50(2), 812-836. doi: 10.1177/0049124118782539

American Association of Public Opinion Research (AAPOR) (2016). Standard definitions. Final dispositions of case codes and outcome rates for surveys. Retrieved October 19, 2021, from: www.aapor.org/Standards-Ethics/Standard-Definitions-(1).aspx

Bundesministerium des Innern, für Bau und Heimat (n.d.). Meldewesen. Retrieved October 19, 2021, from: www.bmi.bund.de/DE/themen/moderneverwaltung/verwaltungsrecht/meldewesen/meldewesen-node.html

Deutsche Post Direkt (2020). Zusatzinformation datenschutzkonforme Adresslösungen. Retrieved October 19, 2021, from: www.deutschepost.de/de/d/deutsche-postdirekt/deutsche-post-direkt-datenschutz.html

Dillman, D. A., Smyth, J. D., \& Christian, L. M. (2014). Internet, phone, mail, and mixed mode surveys: The tailored design method (4th ed.). New York: John Wiley \& Sons.

European Social Survey (2017). ESS Round 8 (2016/2017) Technical Report. London: ESS ERIC. Retrieved October 19, 2021, from: www.europeansocialsurvey.org/data/download.html?r=8

Harter, R., Battaglia, M.P., Buskirk, T.D., Dillman, D.A., English, N., Fahimi, M. ... Zukerberg, A.L. (2016). AAPOR Report: Address-based Sampling. Retrieved October 19, 2021, from: www.aapor.org/Education-Resources/Reports.aspx

Link, M. W., Battaglia, M. P., Frankel, M. R., Osborn, L., \& Mokdad, A. H. (2008). Comparison of Address-Based Sampling (ABS) Versus Random-Digit Dialing (RDD) for General Population Surveys, Public Opinion Quarterly, 72(1), 6-27, doi: $10.1093 / \mathrm{poq} / \mathrm{nfn} 003$

Lohr, S. L. (2009). Sampling: Design and Analysis. Pacific Grove, CA: Duxbury Press. 
Maineri, A. M., Scherpenzeel, A., Bristle, J., Pflüger, S-M., Butt, S., Zins, S., Emery, T., \& Luijkx, R. (2017). Evaluating the quality of sampling frames used in European crossnational surveys. SERISS. Retrieved October 19, 2021, from: www.seriss.eu/resources/deliverables/

Poulain, M. \& Herm, A. (2013). Central Population Registers as a Source of Demographic Statistics in Europe. Population, 68(2), 183-212. doi: 10.3917/popu.1302.0215

Rammstedt, B., John, O. P. (2007). Measuring personality in one minute or less: A 10-item short version of the Big Five Inventory in English and German. Journal of Research in Personality, 41(1), 203-212. doi: 10.1016/j.jrp.2006.02.001

Salentin, K. (2014). Sampling the Ethnic Minority Population in Germany. The Background to "Migration Background". methods, data, analyses, 8(1), 28. doi: 10.12758/mda.2014.002

Stadt Mannheim (n.d.). Einwohner mit Migrationshintergrund. Retrieved October 19, 2021, from: www.mannheim.de/de/stadt-gestalten/daten-undfakten/bevoelkerung/einwohner-mit-migrationshintergrund

Stadt Mannheim (2020). Einwohnerbestand 2019 in kleinräumiger Gliederung. Statistische Daten Mannheim, No 1/2020. Retrieved October 19, 2021, from: www.mannheim.de/de/stadt-gestalten/daten-und-fakten/bevoelkerung Wasmer, M., Blohm, M., Walter, J., Jutz, R., \& Scholz, E. (2017). Konzeption und Durchführung der „Allgemeinen Bevölkerungsumfrage der Sozialwissenschaften“ (ALLBUS) 2014. GESIS Papers 2017|20. Mannheim, Germany: GESIS - Leibniz Institute for the Social Sciences. Retrieved October 19, 2021, from: www.gesis.org/allbus/inhalte-suche/methodenberichte 